\title{
0 corpo envelhecido: percepção e vivência de mulheres idosas *
}

FERNANDES, M.G.M.; GARCIA, L.G.The aged body: perception and experience of elderly women. Interface - Comunic., Saude, Educ., v.14, n.35, p.879-90, out./dez. 2010.

This qualitative study aimed to analyze aged women's perception and experience concerning their bodies, considering the gender perspective. It was carried out in the elderly group Juventude Acumulada, located in the popular neighborhood Cruz das Armas, in the city of João Pessoa, northeastern Brazil. The empirical material was collected through individual semi-structured interviews and reflection workshops, involving eighteen senior women, and was examined by means of discourse analysis. The results show that some senior women see their bodies as fragile, modified, sick and ugly bodies; bodies that bring them negative experiences. On the other hand, others demonstrate satisfaction with their corporal dimension, noticing it as still beautiful and conserved. As for the determinants of their physical aging, the women mentioned maternity, overload of domestic work and domestic violence.

Keywords: Aging. Old age. Gender. Body.
Este estudo, de natureza qualitativa, teve como objetivo analisar a percepção e vivência de mulheres idosas acerca de seus corpos, considerando a perspectiva de gênero. Sua efetividade se deu no grupo de convivência de idosos Juventude Acumulada, localizado no bairro popular de Cruz das Armas, do município de João Pessoa, PB. O material empírico foi obtido por meio de entrevistas individuais semiestruturadas e oficinas de reflexão, envolvendo 18 mulheres idosas, e trabalhado pela análise de discurso. Os resultados apontam que algumas idosas veem seus corpos como frágeis, modificados, doentes e feios, trazendo-lhes vivências negativas. Já outras demonstram satisfação com sua dimensão corporal, percebendo-a ainda bonita e conservada. Quanto aos determinantes do seu envelhecimento físico, as depoentes referiram a maternidade, sobrecarga de trabalho doméstico e violência conjugal.

Palavras-chave: Envelhecimento. Velhice. Gênero. Corpo.

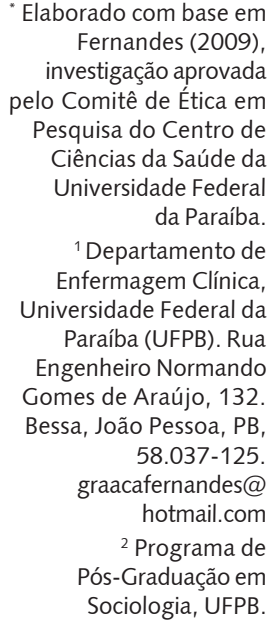

"Elaborado com base em Fernandes (2009), investigação aprovada pelo Comitê de Ética em Pesquisa do Centro de Ciências da Saúde da Universidade Federal da Paraíba.

${ }^{1}$ Departamento de Enfermagem Clínica, Universidade Federal da Paraíba (UFPB). Rua Engenheiro Normando Gomes de Araújo, 132. Bessa, João Pessoa, PB, 58.037-125. graacafernandes@ hotmail.com 2 Programa de Pós-Graduação em Sociologia, UFPB. 


\section{Introdução}

O envelhecimento constitui um processo que, no plano individual, implica trajetórias de vida e, no plano coletivo, se constrói sob diferentes influências de ordem sociocultural. Já a velhice denota o estado de "ser velho", ou seja, a condição resultante do processo de envelhecimento que gerações têm vivenciado no âmbito de contextos específicos de seu ciclo vital (Lima, Silva, Galhardoni, 2008). A natureza da experiência desses processos influencia a percepção do corpo envelhecido por parte dos idosos.

Vale ressaltar que o corpo humano como sistema biológico é afetado, também, pela religiosidade, pela ocupação, pelo grupo familiar, pela classe e por outros intervenientes sociais e culturais, a exemplo do gênero (Rodrigues, 2006). Considerando essa perspectiva, o corpo é a interface entre o social e o individual, entre a natureza e a cultura, entre o fisiológico e o simbólico (Le Breton, 2007).

Assim sendo, o comportamento evidenciado pelos idosos com relação à vivência de sua corporeidade é modelado representacional e socialmente. É usual percebermos, com o olhar do senso comum, que eles ostentam posições e condutas que advêm da dimensão natural inscrita em seus corpos, por meio do social, especialmente as mulheres.

As diferenças biológicas constituem os traços estruturais em torno dos quais as sociedades humanas acrescentam diversos detalhes para definir socialmente o que significa o homem e o que significa a mulher (Le Breton, 2007). Considerando isso, incapaz de pensar tais diferenças, o discurso médico impingiu à mulher a representação que a subordina a uma matriz biológica e procriadora, destinando ao trato do seu corpo um nível de intervenção mais acentuado.

Segundo Barros (2004), o cuidado e a intervenção no corpo feminino se iniciam cedo na trajetória de vida das mulheres e, hoje, alcançam a velhice por meio do controle dos sinais corporais do envelhecimento com cirurgias, reposições hormonais, remédios e outros, considerando o poder aquisitivo e a pressão simbólica presentes sobre cada classe social.

Nesse cenário, os corpos femininos tornam-se o que Foucault (1987) chamou de corpos dóceis; aqueles cujas forças e energias estão habituadas ao controle externo, à transformação e ao aperfeiçoamento, menos orientados para o social (Bordo, 1997). Nesse mesmo entendimento, Bourdieu (1999) ressalta que o mundo social exerce uma espécie de "golpe de força" sobre os sujeitos e imprime, em seus corpos, não apenas um modo de estar e de ser, mas todo um programa de percepção. O autor destaca ainda que a vivência dessa realidade, por parte dos indivíduos, é diversificada conforme o gênero e a geração.

Motta (2002) e Negreiros (2004) salientam que a velhice afeta de modo diferencial homens e mulheres. Como sujeitos que viveram processos socializadores muito diversos em sua juventude e trajetória geral de vida, por mais que tenham, no processo de envelhecimento, experiências que sejam ou aparentem ser comuns à condição etária, a condição de gênero enseja experiências, papéis e representações distintas, o que pode influenciar, também de modo diferencial, o modo de o idoso perceber e vivenciar sua velhice e sua corporalidade.

Attias-Donfut (2004) discorre que as desvantagens femininas na velhice não se limitam a sua frequente inferioridade econômica, sendo elas significativas também num plano mais simbólico, que é o da identidade pessoal associada à imagem corporal. Considerando nossa experiência no trato com idosos tanto na assistência à saúde como na pesquisa, bem como no âmbito de grupos e na comunidade, também verificamos as observações aqui pontuadas.

Não obstante, nem sempre as expectativas dos que lidam com as questões relativas ao envelhecimento correspondem às demandas das mulheres referentes à sua senescência, emergindo, assim, a importância de desvelarmos seus posicionamentos ante tal realidade com base em seus próprios relatos, o que nos conduziu à realização deste estudo, cujo objetivo foi analisar a percepção e vivência de mulheres idosas acerca de seus corpos, considerando a perspectiva de gênero. 


\section{Estratégias metodológicas}

Este estudo, de caráter qualitativo, que expõe o olhar de mulheres sobre seu corpo envelhecido, foi efetivado no período de abril a junho de 2008, no grupo de convivência de idosos Juventude Acumulada, localizado no bairro popular de Cruz das Armas, do município de João Pessoa, PB, tendo como participantes 18 mulheres, de baixo nível socioeconômico e instrucional, que aceitaram, livremente, participar da investigação após a pesquisadora esclarecer seus objetivos e seus passos operacionais.

Para a produção do material empírico, utilizamos duas estratégias: entrevista individual semiestruturada e oficina de reflexão. Quanto às entrevistas, estas foram subsidiadas pelas questões: pensar no corpo envelhecido lhe traz que sentimentos?; como a senhora percebe seu corpo nessa fase da vida?; pensando em toda a sua vida como mulher, o que mais contribuiu para o envelhecimento de seu corpo?. Os depoimentos foram gravados em fita cassete e, logo após cada entrevista, eram transcritos, em sua íntegra, pelas pesquisadoras.

Quanto às oficinas, foram realizadas duas: na primeira, as mulheres, após um período de descontração com atividades de relaxamento físico e mental, elaboraram seus corpos em argila e, posteriormente, completaram a frase: ao construir o meu corpo na velhice veio em minha mente...; na segunda oficina, proporcionamos às idosas um encontro com o espelho e lhes solicitamos que, concomitantemente a essa contemplação de sua imagem corporal, tentassem transmitir, por meio da linguagem verbal, sentimentos e percepções que vieram às suas mentes sobre o seu corpo.

A análise do material empírico apreendido ao longo da coleta de dados foi realizada com base na proposta de análise de discurso de Fiorin (2005). Esse procedimento teve início com a impressão, leitura e releitura dos discursos e recorte dos textos que continham os temas geradores das categorias referentes ao posicionamento social das idosas relativo ao objeto em questão, o qual foi ancorado no referencial de gênero. O enfoque básico da análise de discurso, na perspectiva de Fiorin (2005), é a compreensão de que o discurso é uma posição social, devendo, assim, ser analisado.

\section{Resultados e discussão}

As percepções e vivências das mulheres relativas aos seus corpos no contexto do envelhecimento, expressas no âmbito das entrevistas, bem como das oficinas de reflexão, convergiram em três categorias: "as transformações negativas da velhice sobre o corpo"; as "lembranças do corpo jovem" e a "satisfação com o corpo". A categoria relativa às transformações negativas da velhice sobre o corpo foi subsidiada por discursos que apontam para modificações na aparência - pele enrugada, cabelos brancos - e alterações da saúde, expressando que o tempo deixou sobre ele suas marcas:

"que susto! Quando eu era nova, eu era um chuchu; agora, sou um maracujá murcho, mas me amo assim mesmo". (sra. D, 69 anos)

"como eu era linda! Hoje estou tão diferente! O rosto envelhecido, com rugas. Meus cabelos estão brancos. Os dentes não são mais os mesmos. Minha pele não é lisinha. O corpo não é mais durinho. A saúde é pouca. Não posso mais correr. Saudades!". (sra. L, 67 anos)

"como o meu corpo mudou! A flexibilidade dos meus seios, as rugas em meu rosto! Não tenho a ligeireza de antigamente, tudo mudou. É um corpo cansado, cheio de dor, com muita artrose e precisando de cuidados físicos. Esse corpo quer destruir a minha saúde". (sra. C, 70 anos)

“quando me contemplei no espelho, me veio à mente como o tempo muda a gente. Eu era bonita. Mas, hoje vejo a diferença: a pele envelhecida. Mas, tudo tem seu tempo, eu já tive meu momento". (sra. N, 61 anos) 
"acho que, quando a gente se olha no espelho e não gosta mais, é só na velhice. Eu não tenho mais vontade. Quando eu era novinha, casadinha de novo, eu adorava me arrumar no espelho, mas, agora, eu não ligo". (sra. D, 69 anos)

Se antes, quando jovens, as idosas procuravam o espelho porque este servia para confirmar sua autoestima, agora, que mostra a imagem do antimodelo, quiçá, deve ser evitado, para não "desconfirmar" a mesma. Tal imagem esboça nelas uma reação que sintetiza o sentimento de todas: "que susto!" Essa reação se consubstancia quando uma das mulheres percebe a metamorfose de um chuchu num maracujá murcho, inscrita na sua própria dimensão corporal, condição difícil de ser assimilada, apesar do sentimento de resignação:

\section{"[...] hoje vejo a diferença [...]. Mas, tudo tem seu tempo, eu já tive meu momento!".}

Assim, as mudanças corporais percebidas pelas mulheres conduziram-nas, a exemplo dessa senhora, a elaborarem uma ressignificação de seus corpos e do sentido de suas vidas. Essa ressignificação se tornou possível graças à aceitação da mudança da imagem e das funções corporais, emergindo uma conformação frente a um evento ao qual não se pode resistir de modo absoluto - o envelhecimento. Ante essa situação, as mulheres se confortam com as lembranças do corpo jovem:

"veio em minha mente os anos cinquenta, quando eu brincava com as minhas irmãs, fazendo esse mesmo corpo, só que eu era magrinha, bem despreocupada. Hoje em dia, é diferente, é tanta preocupação!". (sra. A, 78 anos)

"este corpo envelhecido me trouxe lembranças. Lembranças da minha mocidade. De quando eu era mais forte, cheia de pensamentos e projetos". (sra. S, 65 anos)

"Ah, espelho! Quem eu era, como estou hoje?". (sra. P, 70 anos)

Segundo Eco (1989, p.106), "o espelho registra aquilo que o atinge de forma como o atinge. Ele diz a verdade de modo desumano, como bem sabe quem - diante do espelho - perde toda e qualquer ilusão sobre a juventude". Mesmo que se queira negar a velhice, seus primeiros e mais evidentes sinais se manifestam na aparência, e isto ninguém ignora, de forma que o espelho passa a ser o principal acusador de sua manifestação, o grande vilão.

Com esse mesmo sentimento de repulsa da velhice, ante o espelho, Simone de Beauvoir fecha sua obra "La force des choses", publicada quando ela tinha 55 anos, com a seguinte descrição:

[...] No fundo deste espelho, a velhice me espreita [...] Ela me tem. Muitas vezes me detenho, ofuscada, diante desta incrível coisa que é o meu rosto. Compreendo Castiglione que tinha quebrado todos os espelhos [...] Vejo meu antigo rosto onde se instalou uma doença da qual não vou me curar. [...] A velhice me infecta também o coração [...] A morte não é mais, na distância, uma aventura brutal; ela obceca meu sono; acordada, sinto sua sombra entre o mundo e mim mesma: ela já começou. (Beauvoir, 1963, p.198)

Ao descrever seu autorretrato na velhice, Swain $(2003$, p.2) expressa:

[...] Seria eu a outra de mim mesma? Minha imagem no espelho é de uma estrangeira, renovada cada dia, aqui uma dobra, ali uma ruga, uma expressão nos olhos, esta tristeza que se acumula na experiência, a neve que, cada vez mais, possui meus cabelos.

No entendimento de Dourado (2006), o envelhecimento do "corpo biológico", aquele sobre o qual não há palavra que imponha ordem, mostra-nos uma imagem não mais condizente com o ideal que guardamos. A imagem do espelho não corresponde à imagem de memória, pois antecipa ou confirma a velhice, enquanto a imagem da memória se mantém idealizada. 
Motta (2002) discorre que há sempre um sentimento de brusquidão na (auto) percepção do corpo envelhecido, especialmente pelo sentimento em relação ao que lhe acontece: enrugamento, encolhimento, descoramento dos cabelos, enfeiamento, menor agilidade, problemas de saúde e outras perdas.

Neste caso, sendo o corpo um veículo da denúncia dos limites, ele produz angústia e dor. Como colocou Elias (2001, p.80), "não é fácil imaginar que nosso corpo, tão cheio de frescor e muitas vezes de sensações agradáveis, pode ficar vagaroso, cansado e desajeitado. [...] No fundo, não o queremos". Talvez por isso, Goldfarb (1998, p.23) saliente que "a velhice, como alguma coisa da ordem do diabólico, não pode ser nomeada sem provocar medo e rejeição".

Segundo Py e Scharfstein (2001), no curso do envelhecimento, o ser humano é impelido a confrontar a desqualificação do corpo envelhecido, marcada pelos limites inexoráveis do tempo que marcam essa fase da vida. Esses limites são representados, não só pelas modificações estéticas do corpo, mas, também, pelo seu adoecimento, situação expressa de forma muito nítida na fala das mulheres: "a saúde é pouca - muita artrose, muitas dores [...]. Não tenho a ligeireza de antigamente"; "[...] Esse corpo quer destruir minha saúde [...]. É um corpo que precisa de cuidados físicos".

Assiste-se, assim, a um verdadeiro desfile de órgãos deteriorados, membros desobedientes e sintomas intermináveis. Nesse contexto, o corpo deixa de ser aliado confiável para se converter em um inimigo que é necessário controlar e dele cuidar constantemente (Goldfarb, 1998).

Ante essas faltas (saúde, agilidade, beleza) evidenciadas num corpo que é o limite e a extensão do contato/relação com o mundo, as idosas que não gostam de seus corpos apresentam, como indicadores comuns, o recordar do corpo jovem que possuíam tempos atrás, na mocidade. Elas comparam as atividades executadas quando jovens e atualmente, em função do corpo já estar cansado, envelhecido, já não respondendo com eficiência, julgam possuir um corpo de certa forma imperfeito ou "in-válido", como refere Virilio (2000). Nesse processo, percebemos que a expressão "minha mocidade" traz em si um conjunto de representações feitas sobre o passado, que, ressemantizado, passa a antagonizar com o presente.

Vale salientar que o corpo revela os meandros e as curvas da história pessoal, incluindo a capacidade do indivíduo de transgredir, reagir e autoafirmar-se. Assim, na circularidade desse movimento, outras idosas demonstraram satisfação com seu próprio corpo, quebrando possíveis preconceitos relativos ao corpo envelhecido, atribuindo-Ihe beleza e outras características nobres, talvez por estarem atreladas a outra imagem interna de si mesmas, mais importante e forte do que sua aparência externa:

\footnotetext{
"meu corpo é de grande importância na minha vida. Gosto muito do meu corpo, sinto-me amada pelo meu corpo. Envelhecido, mas bem conservado". (sra. S, 65 anos)

"ao construir meu corpo, refleti e lembrei como ele era. Com o tempo, houve transformação. Mas, estou feliz com meu corpo, a transformação é natural; só fiquei assim ressecada". (sra. C, 70 anos)

"sou idosa, mas me cuido, ainda me acho bonita. Me maquio. Agora, pouquinho. Gosto de ficar bonita só pra mim. Nessa idade a gente tem que ser mais reservada. Também já tô na menopausa". (sra. O, 63 anos)
}

Com a ideia de resistência, não estamos nos reportando especialmente aos recursos tradicionais de "correção" da natureza, tais como o uso dos recursos biotecnológicos destinados a disfarçar as intempéries do tempo sobre o corpo; até porque as senhoras deste estudo não têm acesso a tais dispositivos, dada a sua pobreza material, sendo o tema central de suas vidas a luta diária pela sobrevivência, a preocupação com filhos e netos, a doença, o abandono. Referimo-nos a processos de reflexão, representações e comportamentos que Debert (1994) define como mecanismos que se destinam a desnaturalizar o processo de envelhecimento, colocando-o, também, como uma questão de autoconvencimento, como um modo de sobrevivência e resistência ao modelo de construção social do idoso, ou "ideologia da velhice", que tem, como característica fundamental, "ocultar e desconhecer os diferentes modos de viver, sofrer e suportar a velhice" (Haddad, 1986, p.27). 
Entre os rótulos presentes na "ideologia da velhice", destaca-se o da velhice assexuada. Nesse pressuposto, corpo e sexo são categorias que foram exiladas estritamente ao espaço privado, importando, na maioria das vezes, somente os sujeitos mais jovens, justificando a preocupação da idosa em "ser mais reservada", afetiva e sexualmente, pois, "já tá na menopausa".

Vale salientar que a menopausa, assim como a velhice, também é uma construção social que, para Swain (2003, p.6), "promove a recriação do corpo doente, todas histéricas! Por definição, feminino". Considerando as mulheres jovens, esta reapropriação é realizada pelos discursos sobre a TPM (tensão pré-menstrual), que reduz as mulheres a seus hormônios (Rohden, 2008).

Na nossa cultura, o desequilíbrio hormonal e o fim do ciclo reprodutivo, historicamente, foram considerados a porta de entrada da construção do envelhecimento das mulheres, para a retirada dos encantos da sua beleza corporal e, ainda, para o declínio de sua sexualidade. Até as próprias idosas entram nesse ageism.

"O problema do meu corpo é a menopausa [...] Quando as regras pararam, parei o sexo, também já não tinha vontade. Aí veio pele seca, grossa, calor demais, muitos problemas. $O$ corpo ficou esquisito, diferente! Com pouca saúde". (sra. Q, 66 anos)

Percebe-se, nesse discurso, que a interpretação da depoente, relativa à menopausa, e suas reações frente à vivência desse processo biológico são influenciadas por referências sociais negativas feitas à mulher menopausada, que a tratam como um ser de corpo esquisito, afligido por calor, seco e assexuado, em contraste com o corpo masculino que, por não vivenciar tal fenômeno, não constitui objeto de tais mitos ou preconceitos.

Esse imaginário relativo à menopausa ainda está, fortemente, por ser desconstruído, sendo revigorado pela indústria farmacêutica e cosmética, que aufere imensos benefícios para o trato de seus sinais e sintomas com a venda de produtos antimenopausa, antivelhice, antirrugas, anticelulite produtos viva-a-juventude! (Swain, 2003).

Apesar de o tema sexualidade ser tratado pelas mulheres com muita cautela, as quais, muitas vezes, se preocupavam mais em velar o assunto do que desvelá-lo, encontramos, na fala da Sra. P, de 70 anos, uma contraposição à velhice assexuada, pois, para ela, seu corpo é jovem, desejoso e sexuado:

“pra mim, meu corpo não fica velho. Eu sinto até o amor [desejo sexual]. Eu sinto saudades. Tem gente que diz que não sente, mas é mentira. $O$ amor é coisa muito boa. Sinto saudades da minha mocidade, quando eu namorava, era muito bom [...]". (sra. P, 70 anos)

Apesar da expressão do desejo sexual, a idosa ainda vive na saudade, na impossibilidade física ou psicossocial de buscar um parceiro. Ou seja, inclui-se na categoria dos "inativos sexualmente". Cabe destacar que a regularidade das relações sexuais das mulheres idosas está muito ligada à oportunidade representada pela situação conjugal. Como muitas são viúvas ou não têm parceiros, a primeira consequência deste dado objetivo de suas vidas é a limitação de seus relacionamentos afetivos e sexuais.

A intensidade dessa situação se dá também devido ao fato de os homens idosos viúvos ou solteiros optarem, mais frequentemente, por parceiras mais jovens, pois acreditam ser esta uma das formas de potencializar seu poder e virilidade (Risman, 2005). Para as mulheres idosas, no entanto, as relações afetivas com indivíduos mais jovens ainda passam por uma avaliação negativa no âmbito social, demonstrando, assim, um trato desigual da mulher em relação ao homem por parte da sociedade.

O discurso da Sra. P também dialoga com outros discursos femininos sobre a questão e revela: " $[$...] tem gente [outras mulheres] que diz que não sente [desejo sexual]". Devemos considerar que estas mulheres foram socializadas num tempo em que as regras morais e sexuais eram bastante rígidas, quando o controle sobre a conduta e o comportamento das pessoas era algo muito bem definido pelas instituições, a começar pela família, interferindo, portanto, na expressão da sexualidade e do amor erótico, os quais eram marcados pelo ocultamento.

Historicamente, nesse cenário, à mulher não era permitida a manifestação sexual. Era negado o direito ao orgasmo. Em geral, o homem não se preocupava com essa questão. Muitas desconheciam 
como se davam as relações sexuais, pois eram proibidas de conversar sobre sexo, ensinamento permitido somente aos homens, desde que exercitassem seus instintos com prostitutas. Quanto às jovens, deviam casar virgens e não compartilhar com outros sua intimidade sexual, não podendo, na maioria dos casos, escolher com quem iriam se casar.

Ao abordar essa questão, Giddens (1993) destaca que as mulheres se casavam virtualmente e sem qualquer conhecimento sobre sexo, sendo comum uma mãe dizer para a filha que, depois do casamento, coisas desagradáveis poderiam acontecer. A fala da Sra. H, de 68 anos, reflete essa realidade:
"[...] Pra mim o casamento não foi bom. Casei com ele porque naquele tempo a moça tinha que obedecer aos pais. Como eu era muita nova, morava na roça e não tinha estudo, eu não sabia nada da vida de casal. Sou do tempo em que falar de sexo era pecado. A primeira vez, eu nunca esqueço, foi muito ruim, eu chorei muito, com medo! Depois fui me acostumando, agora, era uma coisa por obrigação; querer mesmo, eu não queria [...] Tive onze filhos.
Aguentei muita coisa por causa dos filhos. Só ele mandava em tudo, e eu fiquei com minha humildade. Agora, faz treze anos que me separei dele, mas de sexo, porque ele continua morando em casa. Depois que fiquei mais velha, resolvi fazer as coisas que quero [sorriso]".

Tomando como referência esse discurso, observamos, entre outros aspectos, como a família, embasada especialmente pela doutrina religiosa predominante nas sociedades ocidentais, regulava o exercício sexual dos indivíduos, especialmente o das mulheres. O casamento tradicional não tinha, como objetivo principal, o prazer, mas, a reprodução.

Apesar de muitas dessas mulheres vivenciarem tal realidade, com o avanço da idade, algumas delas expressam mudanças no âmbito da vivência da relação conjugal, passando a se liberarem e demonstrarem coragem de dizer não ao sexo sem prazer e de assumirem a autonomia do seu corpo, a exemplo da Sra. H: " [...] me separei dele, mas, de sexo, porque ele mora na mesma casa. Depois de velha, resolvi fazer as coisas que quero". Essa mesma postura assume a Sra. M: "sexo com ele nem pensar! Ele fique no canto dele que eu fico no meu. É assim. Não ganhei nada com isso, só doença e velhice".

Não obstante, o corpo e a velhice dessas mulheres, diferentemente da experiência masculina, trazem marcas negativas imprimidas pelas suas condições de vida e de gênero, como mulheres pobres e excluídas do poder, tanto no espaço público como no espaço privado do lar, na vivência da maternidade e, sobretudo, nas relações conjugais, muitas das quais opressoras e violentas. Ao longo de suas vidas, muitas sofreram violência conjugal, com agressão verbal crônica, ameaças, isolamento e humilhação. Foram obrigadas a manter a casa e os filhos bem cuidados e, especialmente, a promover o conforto de seus esposos, ainda que estes as agredissem, resultando em envelhecimento precoce do seu corpo.

Essa triste realidade experimentada pelas idosas nos foi revelada frente à questão: pensando em toda a sua vida como mulher (jovem, adulta, casada, mãe, dona de casa, trabalhadora), o que mais contribuiu para o envelhecimento do seu corpo? Seus discursos apontam que seu envelhecimento corporal decorreu da "maternidade", "da sobrecarga de trabalho doméstico" e, de modo mais consistente, da "violência conjugal" (descrita mais adiante), conforme podemos verificar:

"cada filho que tive fez decair o meu corpo. Eu usava cinta e tudo, mas não teve jeito". (sra. $\mathrm{H}, 68$ anos)

"muitas noites em claro, cuidando dos filhos pequenos. Sofria muito na gravidez, era muito doente. Tudo era muito difícil. Cada parto, eu achava que ia morrer". (sra. D, 69 anos)

"fui muito cobrada na casa, na criação dos filhos. Nunca tive ajuda. Até no resguardo, o repouso era pouco, tinha que cuidar de tudo, mesmo doente. Às vezes ia até pro roçado com o marido! Agora ele só me levava quando eu tava boa, só no tempo da colheita. Isso foi ruim pro meu corpo. Estragou a saúde, né? Eu digo lá em casa. Eu sei". (sra. G, 67 anos) 
Essa realidade de trabalho vivida pela Sra. G guarda identificação com a ideia de Guedes, Silva e Coelho (2007) sobre o casamento e o trabalho doméstico. Para essas autoras, o contrato de casamento também pode ser compreendido como uma relação de trabalho na qual, em troca do sustento e proteção, o marido recebe da esposa o trabalho doméstico e o acesso sexual ao seu corpo. As autoras acrescentam ainda que muitas mulheres, sobretudo algumas idosas de hoje, foram forçadas a participar desse contrato. Os costumes sociais da época destituíam as mulheres da oportunidade de ganharem seu próprio sustento, de modo que o casamento era a única chance de elas constituírem uma vida com mais dignidade.

Esse ideal de dignidade a ser adquirida no contexto do casamento se desfaz nos casos em que este é marcado pelo autoritarismo e pela violência, levando as mulheres a terem seu processo de envelhecimento exacerbado, conforme clarifica esta fala:

\footnotetext{
"o que mais envelheceu meu corpo foi sofrimento. Cana de marido. Ele batia muito em mim. Olhe, meu sofrimento era muito grande. Minha pressão subia, ficava nervosa; até hoje, ainda sou nervosa. O pior foi um dia que ele tava de folga, aí eu fui na casa da minha mãe. Olha, mulher, ele chegou em casa e não me achou. Foi triste. Ele foi me buscar; aí dizia assim: sua safada, se você queria se casar era pra tá em casa [...]. E eu quietinha, assim, só rezando, com medo porque ele parecia um satanás. Mas, não teve jeito, ele pegou assim, tirou o cinturão e me deu uma pisa tão triste, tão cruel, [choro] que, quando a fivela do cinturão batia na minha barriga [gravidez], a menina se encolhia toda [...]. Aí, minha vizinha disse: mulher vá na delegacia! Mas, eu pensei: quem vai pagar aluguel e dar de comer a esses meninos? Eu não tinha emprego, pai tinha morrido [...]. Mas um dia ele bebeu e, quando chegou aí no retorno, o carro matou [...]. Meu Deus, perdoa-me, mas eu me aliviei. Hoje não, minha vida mudou, agora eu tô feliz, venho aqui, converso com minhas amigas, passeio. Minhas filhas trabalham [...], eu tiro a pensão dele. Vivo feliz. Homem? Eu não quero mais. Eu não merecia". (sra. M, 65 anos)
}

Esse discurso revela o controle total do marido sobre o corpo, a vida e a vontade dessa mulher. Tal domínio corresponde a uma espécie de tutela construída e legitimada pela cultura machista oriunda da ideologia da supremacia do masculino sobre o feminino, gerando a violência direcionada à mulher, a qual, segundo Gomes et al. (2007, p.505), consiste em "todo ato de violência de gênero que resulte em agressão física, sexual ou psicológica". Chauí define essa forma de violência sob dois ângulos:

em primeiro lugar, como conversão de uma diferença e de uma assimetria numa relação hierárquica de desigualdade, com fins de dominação, de exploração e opressão. Em segundo lugar, como a ação que trata um ser humano não como sujeito, mas como coisa. Esta se caracteriza pela inércia, pela passividade e pelo silêncio [...]. (Chauí, 1985, p.35)

Essa inércia, passividade e silêncio foram vivências que permearam a vida da Sra. M quando vitimada por seu cônjuge, especialmente porque ela não possuía recursos sociais, emocionais e econômicos para superá-las: "e eu quietinha, só rezando, com medo [...] mas, não teve jeito, ele me deu uma pisa [...] Aí, minha vizinha disse: vá na delegacia! Mas, eu pensei: quem vai pagar aluguel e dar de comer a esses meninos? Eu não tinha emprego [...]". Verificamos, nessa fala, que a violência doméstica - de modo especial no passado, e, ainda na atualidade - tem sido pouco denunciada, na defesa do segredo familiar vinculado à honra ou ao provimento familiar, visto que o agressor, muitas vezes, também é o provedor.

O discurso da Sra. M nos revela, ainda, que essa forma de violência contra a mulher também está associada ao modo como homens e mulheres devem se comportar na vida "a dois" e em sociedade especialmente às crenças que se ligam à hierarquia existente entre o casal, onde o homem se situa no lugar de maior poder, podendo, portanto, definir as regras e o que é certo e errado na convivência conjugal: "[...] sua safada, se você queria se casar era pra tá em casa." Nesse contexto, a violência constitui um ato corretivo ou disciplinar, um contínuo que passa "do corrigir pela conversa para a repreensão por meio da agressão física". 
Na compreensão de Guedes, Silva e Coelho (2007), a violência contra a mulher pode ser explicada como um fenômeno que se constitui a partir da naturalização da desigualdade entre os sexos, que se assenta nas categorias hierárquicas, historicamente construídas como um dos mecanismos ideológicos capazes de legitimar o status quo, entre os quais se encontram as classificações sociais e, aqui, a classificação sexual.

A classificação sexual permite que uma das partes do contrato conjugal exerça a dominação sobre a outra parte. Na dominação entre os sexos, na cultura, sobretudo latino-americana, o sexo masculino exerce a dominação física e psíquica, com legitimidade social. Essa dominação rebaixa as mulheres, desqualificando o "outro" da relação como algo "natural" e insuperavelmente inferior, porque biologicamente diferente (Guedes, Silva, Coelho, 2007).

Independente dos seus determinantes, os efeitos relacionados com o trauma da situação de violência na vida e na saúde das mulheres são exacerbados pelo fato de o agressor ser alguém de sua intimidade, com quem divide uma relação permeada por sentimentos afetivos, o que eleva a sensação de vulnerabilidade e traição, conforme menciona a Sra. M: "eu não merecia".

Essa situação de desigualdade e de violência experimentada pelas mulheres idosas ao longo de suas vidas contribui para o fato de muitas delas admitirem que sua pouca força física representa uma inferioridade "natural", fazendo com que algumas se reconheçam, especialmente a partir da dinâmica de suas relações conjugais ou de afeto/poder, num corpo mais fraco que aquele evidenciado pelos homens - crença que guarda consonância com aquela referida pelos homens:
“o corpo do homem é mais resistente. A prova é que eu me casei com um homem de 75 anos, e eu tinha 52 anos, e ele era normal. Morreu normal. Talvez, se fosse uma mulher, fosse diferente". (sra. C, 70 anos)
"eu acho que o corpo do homem é melhor do que o da mulher. Quando o homem vem adoecer, é porque o negócio tá demais! Eles são sem-vergonhas, muitos só querem saber de caçar mulher nova. Só querem ser o tal. Muitos nem fazem nada! [...]. Por isso, eles têm problema na próstata, é porque eles vadiam demais quando são novos [...]. E nós, é o útero, né? As mulheres são tudo arrancadas [histerectomizadas], coisadas! Eu sou queimada, há muitos anos. Mas, fiquei boa, graças a Deus!". (sra. O, 63 anos)

Segundo Le Breton (2007), as características físicas e morais não dependem de um gráfico que fixaria ao homem e à mulher um destino biológico, elas são construídas socialmente. Para Grosz (2000), o pensamento dicotômico (corpo masculino e corpo feminino) necessariamente hierarquiza e classifica os dois termos polarizados, de modo que um deles se torna o privilegiado, e o outro, sua contrapartida suprimida, negativa. A autora acrescenta que, no âmbito desse pensamento, procuram-se conter as mulheres no interior de corpos que são representados, até construídos, como frágeis.

Essa concepção de fragilidade do corpo feminino também emerge de modo simbólico, por meio de uma visão místico-religiosa do corpo, em que a Sra. J associa o corpo da mulher ao de Nossa Senhora, sendo "a mama, o seio ou o busto" o órgão mais sublime, tanto por sua beleza como por sua função.

“[...] Nós representamos Nossa Senhora, e nosso corpo é tão bonito que nós temos um seio pra amamentar nosso filho. É uma coisa que o homem não tem. O nosso corpo é tão perfeito que nosso rosto é lindo como o de Nossa Senhora [...]". (sra. J, 73 anos)

A percepção do corpo feminino revelada pela Sra. J está fundada, segundo Scott (1990), em símbolos culturalmente disponíveis tidos como referência ou modelagem de comportamento, a exemplo de Nossa Senhora, na tradição ocidental, que representa a pureza, a abnegação, a santidade e a sexualidade contida. Além disso, sua vivência em um corpo que lhe possibilite a maternagem surge como um forte orientador de sentido para a sua vida enquanto mulher.

Segundo Chodorow (1990), a capacidade da mulher para maternar e suas habilidades para retirar disto gratificação são fortemente internalizadas e psicologicamente reforçadas, sendo construídas ao 
longo do seu processo de desenvolvimento, no interior da estrutura psíquica feminina. Não se trata de um "produto da biologia" nem de um preparo intencional para a função. A organização social de gênero afeta, por conseguinte, os processos e as estruturas inconscientes tanto de homens como de mulheres (Saffioti, 1992).

A visão dualista que se perpetua sobre a compreensão do corpo, bem como a contribuição da igreja com a sua percepção como carne, em oposição ao espírito, e, no caso da mulher, destinado a procriar, orienta a representação da Sra. Q acerca do seu próprio corpo:

"eu entendo assim: o corpo da mulher foi criado por Deus para a gestação, para ter os filhos [...], e o coração pra sentir, pra se livrar do perigo da carne. Acho que na velhice nós estamos mais perto de Deus porque nós passamos a ter mais sentimento, estamos mais calmas, mais longe das coisas do corpo, Assim, de contato [corporal], até com o marido! Pra mim, isso é uma virtude da velhice [...]". (sra. Q, 66 anos)

Conforme enuncia essa fala, o corpo é fonte de pecado, sede dos prazeres carnais de que a mulher deve se abster, voltando-se a sua função reprodutiva. Para isso, precisa estar atenta à "voz do coração". Para essa senhora, na velhice, a mulher, ante a finitude da função procriativa, tem maior possibilidade de se aproximar do Divino por estar mais ligada aos sentimentos, longe dos prazeres oriundos do contato físico com seu próprio corpo ou com outros corpos, especialmente, o masculino.

$\mathrm{Na}$ análise da percepção do corpo envelhecido pelas mulheres, encontramos ainda o discurso da Sra. $F$, o qual se apropria de um posicionamento que, considerando o gênero, homogeiniza o corpo na velhice a partir de uma decrepitude genérica:

“[...] eu acho tudo igual, porque vai despencando tudo por igual, né? Porque, na mulher, vai caindo os peitos; nos homens, vai caindo os testículos e aí vai caindo. A mulher, vai caindo o semblante; o homem, também. Então, eu acho que o corpo velho é igual. Velho é velho!". (sra. F, 66 anos)

Esse sentimento, nada incomum, demonstra bem a dificuldade de construção de uma identidade positiva para o velho, sobretudo quando referida ao corpo. Sua aparência desgastada, permanentemente retocada - às avessas - pelo tempo, e sua funcionalidade, algumas vezes não sincronizada com a mente, imprime, nos indivíduos, dificuldade para aceitá-lo.

\section{Considerações finais}

Os dados produzidos neste estudo revelam uma realidade que foi recortada e que traduz experiências e vivências que foram gestadas de modo particular, retratando, em parte, a realidade das mulheres idosas que nos falaram dos seus corpos no contexto da velhice.

Apesar da intrínseca relação de gênero verificada nos dados encontrados nesta investigação, não podemos desconsiderar que eles também trazem uma delimitação de classe social, pois dela participaram mulheres de baixo nível socioeconômico e instrucional. Assim, a pesquisa remete a outra investigação, envolvendo idosas inseridas em classe social média e alta, o que poderá modificar as representações dos idosos no tocante a sua corporalidade, afetando, inclusive, as relações de gênero.

Por fim, numa tentativa de síntese, ressaltamos que as reflexões acerca do corpo envelhecido aqui apresentadas refletem a perspectiva binária do mundo: o corpo não é velho senão em relação a um referente - o jovem. Segundo Swain (2003), a polarização de grupos, divididos em juventude versus velhice, retoma, de fato, a naturalização dos corpos, remetendo-os ao biológico, à evolução, à superfície pré-discursiva. 


\section{Colaboradores}

As autoras trabalharam juntas em todas as etapas do manuscrito.

\section{Referências}

ATTIAS-DONFUT, C. Sexo e envelhecimento. In: PEIXOTO, C.E. (Org.). Família e envelhecimento. Rio de Janeiro: FGV, 2004. p.89-105.

BARROS, M.M.L. Envelhecimento, cultura e transformações sociais. In: PY, L. et al. (Orgs.). Tempo de envelhecer: percursos e dimensões psicossociais. Rio de Janeiro: Nau, 2004. p.39-60.

BEAUVOIR, S. La force des choses. Paris: Galimard, 1963.

BORDO, S.R. O corpo e a reprodução da feminilidade: uma apropriação feminista de Foucault. In: BORDO, S.R.; JAGGAR, A.M. (Orgs.). Gênero, corpo, conhecimento. Rio de Janeiro: Rosa dos Tempos, 1997. p.19-38.

BOURDIEU, P. A dominação masculina. Rio de Janeiro: Bertrand Brasil, 1999.

CHAUÍ, M. Participando do debate sobre mulher e violência. Rio de Janeiro: Zahar, 1985.

CHODOROW, N. Psicanálise da maternidade. Rio de Janeiro: Rosa dos Tempos, 1990.

DEBERT, G.G. Gênero e envelhecimento. Rev. Estud. Fem, v.2, n.3, p.33-51, 1994.

DOURADO, M.C.N. A velhice e seus destinos. A Terceira Idade, v.17, n.37, p.7-15, 2006.

ECO, U. Sobre os espelhos e outros ensaios. Rio de Janeiro: Nova Fronteira, 1989.

ELIAS, N. A solidão dos moribundos: seguido de envelhecer e morrer. Rio de Janeiro: Zahar, 2001.

FERNANDES, M.G.M. A velhice e o corpo envelhecido na percepção e vivência de homens e mulheres idosas: uma análise sob o olhar de gênero. 2009. Tese (Doutorado) - Centro de Ciências Humanas, Letras e Artes, Universidade Federal da Paraíba, João Pessoa. 2009.

FIORIN, J.L. Elementos de análise do discurso. 13.ed. São Paulo: Contexto, 2005.

FOUCAULT, M. Vigiar e punir. Petrópolis: Vozes. 1987.

GIDDENS, A. A transformação da intimidade: sexualidade, amor e erotismo nas sociedades modernas. São Paulo: Ed. Unesp, 1993.

GOLDFARB, D.C. Corpo, tempo e envelhecimento. São Paulo: Casa do Psicólogo, 1998.

GOMES, N.P. et al. Compreendendo a violência doméstica a partir das categorias gênero e geração. Acta Paul. Enferm., v.20, n.4, p.504-8, 2007.

GROSZ, E. Corpos reconfigurados. Cad. Pagu, n.11, p.45-86, 2000.

GUEDES, R.N.; COELHO, A.T.M.C.S.; CARDOSO, E.A. Violência conjugal: problematizando a opressão das mulheres vitimizadas sob olhar de gênero. Rev. Eletron. Enferm., v.9, n.2, p.362-78, 2007. Disponível em: <http://www.fen.ufg.br/ revista/v9/n2/v9n2a06.htm>. Acesso em: 20 jun. 2008.

HADDAD, E.G.M. A ideologia da velhice. São Paulo: Cortez, 1986.

LE BRETON, D. A sociologia do corpo. 2.ed. Petrópolis: Vozes, 2007.

LIMA, A.M.M.; SILVA, H.S.; GALHARDONI, R. Envelhecimento bem-sucedido: trajetórias de um constructo e novas fronteiras. Interface - Comunic., Saude, Educ., v.12, n.27, p.795-807, 2008. 
MOTTA, A.B. Envelhecimento e sentimento do corpo: In: MINAYO, M.C.; COIMBRA JR., C. (Orgs.). Antropologia, saúde e envelhecimento. Rio de Janeiro: Fiocruz, 2002. p.37-50.

NEGREIROS, T.C.G.M. Sexualidade e gênero no envelhecimento. ALCEU, v.5, n.9, p.77-86, 2004.

PY, L.; SCHARFSTEIN, E.A. Caminhos da maturidade: representações do corpo, vivência dos afetos e consciência da finitude. In: NERI, A.L. (Org.). Maturidade e velhice: trajetórias individuais e socioculturais. Campinas: Papirus, 2001. p.117-50.

RISMAN, A. Sexualidade e terceira idade: uma visão histórico-cultural. Textos Envelhecimento, v.8, n.1, p.15-32, 2005.

RODRIGUES, J.C. Tabu do corpo. 7.ed. Rio de Janeiro: Fiocruz, 2006.

ROHDEN, F. O império dos hormônios e a construção da diferença entre os sexos. Hist. Cienc. Saude - Manguinhos, v.15, supl., p.133-52, 2008.

SAFFIOTI, H. Rearticulando gênero e classe social. In: COSTA, A.O.; BRUSCHINI, C. (Eds.). Uma questão de gênero. Rio de Janeiro: Rosa dos Tempos. 1992. p.183-215.

SCOTT, J. Gênero: uma categoria útil de análise histórica. Educ. Realid., v.16, n.2, p.5-52, 1990.

SWAIN, T.N. Velha? Eu? Autoretrato de uma feminista. Rev. Labrys, n.4, 2003. Disponível em: <www.unb.Br/ih/his/gefen>. Acesso em: 9 jun. 2008.

VIRILIO, P. A velocidade da libertação. São Paulo: Estação Liberdade, 2000.

FERNANDES, M.G.M.; GARCIA, L.G.El cuerpo envejecido: percepción y vivencia de mujeres ancianas. Interface - Comunic., Saude, Educ., v.14, n.35, p.879-90, out./dez. 2010.

Este estudio, de naturaleza cualitativa, ha tenido como objetivo el de analizar la percepción y vivencia de mujeres ancianas acerca de sus cuerpos considerando la perspectiva de género. Se ha efectivado en el grupo de convivencia de ancianos Juventud Acumulada, localizado en el barrio popular de Cruz de Armas, en el municipio de João Pessoa del estado brasileño Paraíba. El material empírico se ha obtenido por medio de entrevistas individuales semi-estructuradas y talleres de reflexión, incluyendo a 18 mujeres ancianas y trabajando con el análisis de discurso. Los resultados señalan algunas ancianas ven sus cuerpos frágiles, modificados, enfermos y feos, trayéndoles vivencias negativas. Otras demuestran satisfacción con su dimensión corporal, considerándola todavía bonita y conservada. Referente a los determinantes de su envejecimiento físico, las declarantes se refieren a la maternidad, sobrecarga de trabajo doméstico y violencia conyugal.

Palabras clave: Envejecimiento. Vejez. Género. Cuerpo. 